\title{
Insights into quorum sensing (QS): QS-regulated biofilm and inhibitors
}

\author{
Wen-Si Tan ${ }^{1}$, Jodi Woan-Fei Law², Lydia Ngiik-Shiew Law ${ }^{3}$, Vengadesh Letchumanan ${ }^{2}$, Kok-Gan \\ $\mathrm{Chan}^{4,5^{*}}$ \\ ${ }^{1}$ Illumina Singapore Pte Ltd, Woodlands Industrial Park E1, Singapore \\ ${ }^{2}$ Novel Bacteria and Drug Discovery (NBDD) Research Group, Microbiome and Bioresource Research Strength (MBRS), \\ Jeffrey Cheah School of Medicine and Health Sciences, Monash University Malaysia, 47500 Bandar Sunway, Selangor Darul \\ Ehsan, Malaysia \\ ${ }^{3}$ Faculty of Pharmacy and Pharmaceutical Sciences, Monash University, 381 Royal Parade, Parkville VIC 3052, Australia \\ ${ }^{4}$ Division of Genetics and Molecular Biology, Institute of Biological Sciences, Faculty of Science, University of Malaya, 50603 \\ Kuala Lumpur, Malaysia \\ ${ }^{5}$ International Genome Centre, Jiangsu University, Zhenjiang, China
}

\begin{abstract}
In the environment, bacteria can communicate with a known mechanism called quorum sensing (QS). These bacteria will communicate in a group for social interactions like a multi-cellular organism. It provides significant benefits to the bacteria in host colonization, the formation of biofilms, defense against competitors, and adaptation to environmental changes. The bacteria that organize in biofilms are difficult to control and manage, resulting in a higher dosage of antibiotics to clear the infectious biofilms. Also, many QS-controlled activities are involved in virulence and pathogenicity. Hence, understanding the details of quorum sensing mechanisms, its phenotype regulation (biofilm), and QS inhibitors (which attenuate virulence/pathogenicity) may open a new avenue for controlling bacterial infections.
\end{abstract}

Keywords: Quorum sensing; biofilm; inhibitors; virulence; infections

Received: 19th October 2020

Accepted: 19th November 2020

Published Online: 28th November 2020
*Correspondence: Kok-Gan Chan, Division of Genetics and Molecular Biology, Institute of Biological Sciences, Faculty of Science, University of Malaya, 50603 Kuala Lumpur, Malaysia; kokgan@um.edu.my.

Citation: Tan W-S, Law JW-F, Law LN-S, et al. Insights into quorum sensing (QS): QS-regulated biofilm and inhibitors. Prog Microbes Mol Biol 2020; 3(1): a0000141. https://doi.org/10.36877/pmmb.a0000141.

\section{INTRODUCTION}

Bacteria are a group of microorganisms that can interact with each other and their surroundings via quorum sensing. Quorum sensing is a bacterial cell-to-cell communication process that depends on the release and response to extracellular chemical signaling molecules known as autoinducers ${ }^{[1]}$. These autoinducers will increase in concentration in a synchronized manner with the density of the bacterial cell population. Thus, detecting a minimum threshold concentration of signaling molecules could stimulate an alteration in gene expression ${ }^{[2,3]}$. In other words, QS regulates gene expression as a result of changes in the cell population density. Several types of autoinducers have been identified, and they consist of small peptides, quinolones, and acyl homoserine lactones (AHL). The AHL-based QS system is the most studied among other methods, and AHL molecules are the primary QS signals utilized by Gram-negative bacteria ${ }^{[4]}$. Briefly, a typical AHL-based QS system comprises two primary proteins: LuxI-type protein (cytoplasmic AHL synthase) and LuxR-type protein (AHL-responsive DNA- binding transcriptional regulator $)^{[5,6]}$. The bacterial cells generate AHL signals (synthesized by LuxI-type AHL synthase) at a low basal rate, which can penetrate the cell membrane without using a receptor. Once the threshold concentration of AHL signals is achieved, the signs are sensed by LuxR-type transcriptional regulator protein and thereby produce a LuxR/AHL complex that alters gene expression upon binding to lux box DNA - a conserved site in the promoter region ${ }^{[6-8]}$.

The AHL is known to be involved in regulating different phenotypes, which is strain-dependent through $\mathrm{QS}^{[0,10]}$. In the natural environment, bacteria can sense the cell population density and regulate a wide range of physiological processes, including expressing essential phenotypes such as bioluminescence, biofilm formation, virulence factor production, swarming motility, chemotaxis, toxin secretion, and antibiotic resistance ${ }^{[1,2,2]}$. These QS-regulated phenotypes are also essential for bacteria to successfully establish a symbiotic (beneficial or pathogenic) relationship with higher organisms. This review aims to provide insights 
into the quorum sensing mechanisms, phenotype regulation (biofilm), and the QS inhibitors in which attenuate bacterial virulence/pathogenicity.

\section{BACTERIAL QUORUM SENSING AND BIO- FILM DEVELOPMENT}

The attachment to surfaces is the first step for bacteria forming communities (known as biofilm) that enmeshed in a self-produced polymeric matrix ${ }^{[11,12]}$. The majority of bacterial infections in humans (more than $80 \%$ ) involve biofilm development ${ }^{[13]}$. Notably, biofilm formation is one of the phenotypes which is closely related to QS. The development of biofilm in vitro involves five stages. First, the reversible attachment of bacterial cells to the surface will turn into irreversible attachment mediated by exopolymeric materia[ ${ }^{[14}, 1 \underline{15}$. Fibrinogen and fibronectinbinding proteins are usually found to play a role in this attachment process. Next, microcolonies are formed, and this indicates the beginning of biofilm maturation. The mature biofilms engineered varies, from flat, homogenous biofilms to highly structured 3-dimensional biofilms. The matured biofilm contains cells that are packed in clusters with channels in between to allow water and nutrient transportation and waste removal. The architecture of developed biofilm is often influenced by motility, rhamnolipid production, and extracellular polymeric substance matrix production. AHL-based QS has been shown to affect biofilm formation at the maturation stage. Labbate and colleagues (2004) $)^{[16]}$ proved that a mutation in $S$. liquefaciens acyl-synthase gene, swrI results in thin biofilms that lacked aggregates and filaments as compared to its wildtype's biofilm, which is heterogenous that consist of an aggregation of long filaments of cells. This is further substantiated by work on Burkholderia cepacia H111 with mutations in either cepI or cepR ${ }^{[1]]}$. Both mutants showed defective in biofilm maturation and were only arrested at the microcolony stage of growth compared to the robust biofilms covered with attachment surface formed by the wildtype.

Additionally, the maturation of biofilm is influenced by the LuxS-based QS other than the AHL-dependent pathway ${ }^{[18,19]}$. In Streptococcus mutans, the mutation in luxS resulted in a mature biofilm with decreased biomass as compared with its wildtype. The final stage of biofilm involved aggregation and detachment, dissolution or dispersal of cells from the biofilm to initiate a new biofilm formation. The dispersed cells showed similarity with planktonic cells, which is non-adherent. This dispersal process allows bacteria to colonize new surfaces and spread its virulence effectively within a closed environment. In this final stage of biofilm formation, the cell dispersal was also found to be QS controlled. In Rhodobacter sphaeroides, the mutation in its AHL synthase resulted in hyper-aggregation of cells; but QS's role in this bacteria still remains unknown ${ }^{[20]}$. Other than that, yspR mutant of Yersinia pseudotuberculosis resulted in increased swimming motility ${ }^{[15]}$.

The complex formation of biofilm provides a "room" with a hydrated matrix of microbially produced proteins, nucleic acids, and polysaccharides that allows the cells to act less as individual entities but more as collective living systems $^{[14]}$. Biofilm shields the bacteria by significantly increased in resistance to environmental stresses $(\mathrm{pH}$ fluctuation, high salt, and nutrient fluctuation) or microbially harmful particles (antibiotics and biocides). The exciting point arises the criteria for determining the role of QS in biofilm formation ${ }^{[15]}$. Perhaps it is not surprising that QS indeed plays a major role in biofilm formation, evident by increasing the study of mutant construction experiments that produce pleiotropic phenotypes that affect motility, surface attachment expression, or cell chemistry surface, which is later translated into biofilm formation. However, it would be best if the role of QS could be evaluated by monitoring the signaling process in situ in a developing biofilm in the parental strain and determine if the onset of QS corresponds to any observable transition in bacterial biofilm development that relates with other phenotypes such as incline of antimicrobial tolerance.

\section{USE OF QUORUM SENSING INHIBITORS AS POTENTIAL ANTIPATHOGENS}

The pathogenesis portrayed by bacteria is a multi-factorial process regulated by the production of virulence factors, which causes a variety of bacterial infectious diseases ${ }^{[21]}$. QS could regulate many of the bacterial infectious diseases in humans, animals, and plants. Consequently, QS-regulated biofilm formation plays a vital role in bacterial pathogenesis. This has raised the level of concern in clinical settings and other industrial settings where biofilms pose a significant issue, such as aquaculture, agriculture, wastewater treatment plants, and drinking water processing ${ }^{[22]}$.

The dedication of antibiotics in the early $20^{\text {th }}$ century initiated a new era in treating microbial infections, and they were the most rewarding drug that saves myriad lives ${ }^{[23]}$. However, antibiotics usage over a long time could cause substantial evolutionary stress on the bacterial population and lead to the emergence of multidrug-resistant strains that possessed defensive mechanisms against these antibiotics ${ }^{[24,25]}$. Methicillin-resistant Staphylococcus aureus (MRSA) [26,27], vancomycin-resistant enterococci (VRE) ${ }^{[28]}$, multidrug resistant Salmonella enterica Subsp. enterica ${ }^{[29-31]}$, multidrug-resistant Mycobacterium tuberculosis ${ }^{[32]}$, multidrug-resistant Vibrio parahaemolyticus ${ }^{[33-42]}$ are some dangerous bacterial species that have emerged due to over usage of antibiotic. The emergence of multidrug-resistant bacteria has caught medical attention, and various approaches are now taken to investigate alternative antimicrobials from different sources (e.g., plants and microorganisms) ) $24,43-49]^{2}$ Interestingly, scientists have also considered another approach in recent years by exploring into QS linking to bacterial pathogenicity. The findings into the association of QS and bacterial pathogenicity have been evidently strong as virulence has been greatly reduced in mutants that are defective in QS [21,50,51]. In addition, researchers are actively venture into the investigation of different approaches to interrupt or inhibit QS for the control of bacterial diseases. This inhibition process is generally known as "quorum quenching". Quorum quenching (QQ) can be carried out by the application of enzymatic degradation of autoinducers, 
blockage of autoinducer compounds synthesis, and utilization of inhibitor compounds to block the signal detection $^{[52-54]}$. Therefore, techniques that target the QS pathway could serve as a potential new strategy to attenuate bacterial pathogenicity and inhibition of biofilm formation (Figure 1).

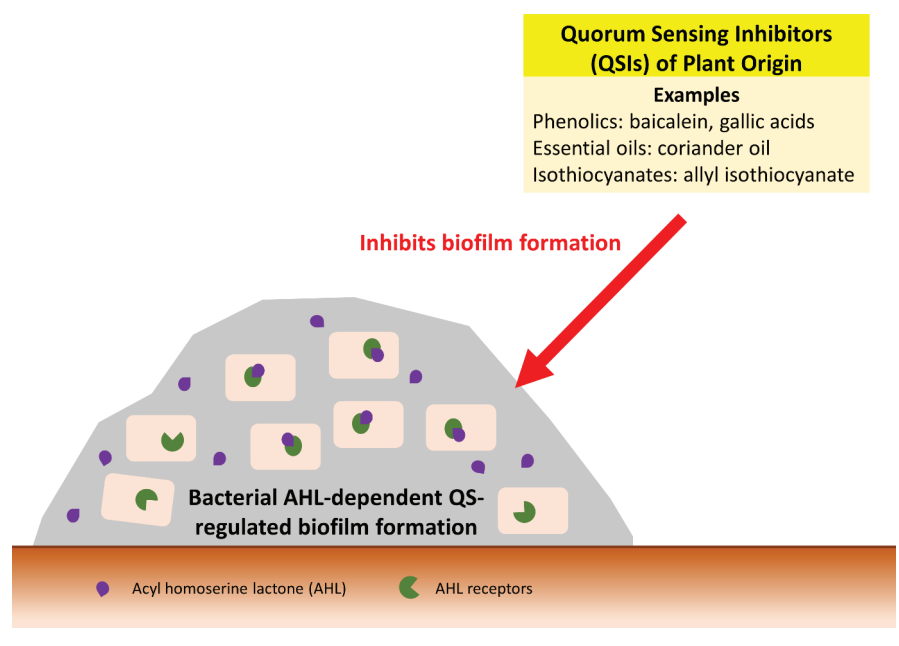

Figure 1. Application of QS inhibitors against biofilm formation.

Halogenated furanone compounds or known as fimbrolides are intensively studied as a group of QS inhibitors ${ }^{[23]}$. They are isolated from red microalga Delisea pulchra, an alga that can produce secondary metabolites that are made up of more than 30 types of furanones. Previous studies had shown that these secondary metabolites could interfere with the AHL-based QS communication circuit. A study performed by Janssens and colleagues (2008) ${ }^{[5 \underline{5}]}$ showed that brominated furanones could prevent biofilm formation of Salmonella serovar Typhimurium at nongrowth inhibiting concentrations. Brominated furanones were also found to meddle with the biofilm formation of several other bacterial species including E. coli, B. subtilis, P. aeruginosa and Streptococcus species. Another study performed by Givskov and colleagues (1996) ${ }^{[56]}$ evident that $100 \mu \mathrm{g} / \mathrm{mL}$ of furanone extracted from $D$. pulchra could inhibit swarming abilities of Serratia liquefaciens. Moreover, Defoirdt et al. (2006) ${ }^{[57]}$ also showed that furanone can inhibit bioluminescence of Vibrio harveyi strain JMH597 at a concentration of $100 \mathrm{mg} / \mathrm{L}$. However, drawbacks of halogenated furanones are too reactive and could cause toxicity towards human cells.

Thus, researchers exert into finding potential quorum sensing inhibitors (QSIs) from various natural sources. It has been proposed that a potential QSI should fulfill specific criteria ${ }^{[22]}$ : (i) small molecule with high efficiency in reducing QS regulated genes, (ii) high degree of specificity with no adverse effect, (iii) chemically stable and resist to host metabolic system, (iv) longer than AHLs to prevent bacteria resistance, (v) do not affect the host microbiome, and (vi) show no toxicity effects towards the host. To date, numerous naturally occurring QSI is presently well established and grouped into various categories. Besides, several QQ enzymes have been discovered from prokaryotes and animal sources. One of the QQ enzymes is AHL-acylase that cleaves acyl side chain. Acylase produces by Streptomyces sp. is similar to acylase I produce by porcine kidney, where both cleaves the acyl chain longer than six carbons ${ }^{[58,59]}$. Some other QQ enzymes are AHL lactonases that produced by Bacillus spp. ${ }^{[60]}$ and mammalian paraoxonases ${ }^{[61]}$ that function to hydrolyze AHL lactone ring. However, researchers have been focusing on exploring potential QSIs from plant extract because it has been anticipated that plant sources are safer for human consumption. These natural compounds are known as secondary metabolites (or phytochemicals), and many classes of these phytochemicals demonstrated their potential as antimicrobials or synergists of other products ${ }^{[62]}$. Recent studies have promoted the potential of these phytochemicals as potential QSIs. As a result, the active compounds have been extracted from plants and their QS inhibition activity has been evaluated by numerous studies (Table 1). Further toxicology study should be performed on these extracted compounds to validate their safety as biopharmaceutical agents.

One of the QSIs consists of phenolic products or polyphenols, which constitute one of the most abundant and omnipresent as plant secondary metabolites (phytochemicals) ${ }^{[63]}$. Phenolics are considered potential QSIs because they are used to treat ailments such as diabetes, cancer, or inflammatory diseases besides having antimicrobial properties. Jagani and colleagues (2009) ${ }^{[64]}$ proved that naturally occurring phenolics could act against biofouling of $P$. aeruginosa. Another study conducted by Vandeputte and colleagues (2010) ${ }^{[65]}$ showed that catechin extracted from Combretam albiflorum reduces elastase, pyocyanin, and biofilm formation $P$. aeruginosa PAO1. They had selected eight types of phenolics, anarcadic acid, polyanarcadic acid, salicyclic acid, polysalicyclic acid, polyphenol, catechin, epigallocatechin, and tannic acid; all eight compounds showed significant reduction towards $P$. aeruginosa biofilm formation. Flavonoids extracted from citrus species such as quercetin and naringenin hinder the biofilm formation of E. coli $\mathrm{O} 157: \mathrm{H} 7$ and $V$. harveyi $\mathrm{BB} 120^{[66,67]}$. Another subclass of phenolics, furocoumarins, shows QSI abilities in which purified furocoumarins - dihydroxybergamottin and 
berggamottin inhibit autoinducer activities $V$. harveyi ${ }^{[68]}$. Girennavar and colleagues (2008) ${ }^{[69]}$ further substantiated that furocoumarins from grapefruit juice inhibited more than $95 \%$ of autoinducer- 1 and autoinducer- 2 activities in $V$. harveyi. Other than that, ferulic acid and gallic acid (grouped under subclass of phenolic acids) were found to block bacterial motility, adhesion, and biofilm formation of E. coli, P. aeruginosa, S. aureus, and Listeria monocytogens ${ }^{[70]}$. A study carried out by Plyuta and colleagues $(2013)^{[71]}$ showed that the usage of 200 $\mu \mathrm{g} / \mathrm{mL}$ of gallic acid reduced the biofilm formation of $P$. aeruginosa PAO1 to $30 \%$. Gallic acid has been proven as a potential QSI. Gallic acid at a concentration of $1 \mathrm{mM}$ resulted in an $80 \%$ reduction of biofilm formation by Eikenella corrodens as demonstrated in the experiment Matsunaga et al. (2010) $)^{[72]}$. As for ferulic acid, application at a concentration lower than eight $\mu \mathrm{g} / \mathrm{mL}$ found to forbid S. aureus' biofilm formation ${ }^{[73]}$.

Other groups of phytochemicals such as isothiocyanates and essential oils could serve as potential QSIs. Isothiocyanates are products formed during glucosinolate hydrolysis, and they are considered the most critical biological active products in plants ${ }^{[74]}$. One of the aliphatic isothiocyanates, allylisothiocyanate, interfered with the adhesion-related genes in $S$. aureus in work done by Lee et al. (2013) $)^{[75]}$. This compound demonstrated to reduce the Pseudomonas sp. planktonic cell growth and the number of cells adhered to the Brassica nigra. Likewise, essential oils have proven to be potential QSIs as they are complex mixtures of volatile compounds synthesized from several plant organs ${ }^{[76]}$. The QS activities of $P$. aeruginosa, Proteus mirabilis, and $S$. marcescens - swarming, production of extracellular polymeric substances and biofilm formation were inhibited upon exposing to methanolic extracts of Cuminum cynimum, where one of the components is methyl eugenol — an essential oil with an aromatic ring ${ }^{[77]}$. This plant-based QSIs may not function as bactericidal compounds; however, the infection process could be interrupted by interfering the bacterial QS and this eventually leads to elimination of pathogens by the host immune system.

\section{BIOTECHNOLOGICAL IMPLICATIONS OF STUDYING QS}

As the number of bacteria that employ QS systems continues to bloom, the research into QS could span a wide variety of potential applications, mostly controlling bacteria growth and activities by interfering with the signaling pathways ${ }^{[78]}$. QS cross talk is also another exciting implication as bacteria always exist in the mixedspecies population, such as biofilms in nature. This could cause an outbreak of infectious diseases or further health complications $^{[79]}$. The study into QS paved the way for discovering various QSIs that is feasible as a treatment for bacterial infections in all living organisms. Given the growing numbers of multidrug-resistant strains, the rational strategy is to control these bacteria's outbreak by manipulating QS properties. Nowadays, scientists are exploiting the possible benefits of understanding the bacterial QS system. Ultimately, this could significantly contribute to many fields, such as improving the water treatment process, preventing bacterial diseases in aquaculture systems, and treating human infections ${ }^{[80]}$.

Another interesting fact of QS is that eukaryotes can recognize bacterial QS molecules. This cross-kingdom interaction alters the physiological adaptation in colonized eukaryotes that modify their defense system, immune responses, hormonal responses, or growth responses ${ }^{[81]}$. Besides creating a pathogenic relationship with higher organisms, the interesting interaction is signaling molecules (AHLs); reported to mediate root growth through biosynthesis of phytohormones. Indole-3-acetic acid (IAA), or known as auxin, is a crucial phytohormone that enhances different developmental processes in plants. IAA production is widely spread among plant-associated bacteria. They can play a critical role in promoting plants' growth and development, especially root elongation ${ }^{[82]}$. Plant growth-promoting bacteria (PGPB) have been extensively studied as potential bio-fertilizers due to increasing pollution by over-usage of chemical fertilizers ${ }^{[83]}$. Biosynthesis of IAA by microbial strain is considered one of the essential criteria to be selected as an efficient PGPB. To date, there is an increasing number of reports stating that QS facilitates the PGPB in enhancing plant growth. As previously reported, treatment of Arabidopsis thaliana roots with $1-10 \mu \mathrm{M}$ of $\mathrm{C} 4$ - and C6-HSL increased the ratio of IAA/cytosine that led to promoted root growth ${ }^{[84]}$. In their study, they found out that the introduction of C6HSL did not induce the systemic resistance and priming effect of $A$. thaliana. They further stated that shortchain AHLs might play a better role in promoting plant growth due to the hydrophobicity of long-chain AHLs. A study substantiates this fact revealed that C6-HSL was transported to the leaves of yam beans and barley leaves but not the C10-HSL ${ }^{[85]}$. Various studies also showed that Rhizobium mutants that were unable to produce AHLs were unable to nodulate legume plants compared to the wildtype $\operatorname{strain}^{[86]}$. These also further support the idea that AHLs could be participating in beneficial plant-bacteria interactions. Thus far, the QS studies could lead us into a different dimension in searching the potential of QS bacteria to contribute beneficially.

\section{CONCLUSION}

It is undeniable that QS plays an essential part in the physiological processes of bacteria. Nonetheless, further studies are still required to characterize the function and pathway-related to QS fully. The occurrence of antibiotic resistance and infections reflects the downside of utilizing antibiotics to treat biofilm linked continual bacterial infections. The application of QSIs has exhibited promising results against biofilm formation; however, the utilization of QSIs as an approach to the battle against multidrugresistant bacteria entails additional investigation. Future work needs to reveal if QSI compounds can be developed as antipathogenic treatment and their successful bacterial eradication mechanisms. 
Table 1. Examples of QS inhibitors (QSIs) from plant origin and its effect on QS activity.

\begin{tabular}{|c|c|c|c|}
\hline $\begin{array}{l}\text { Phytochemical } \\
\text { Group }\end{array}$ & QSIs (Phytochemicals) & Effect on QS Activity & References \\
\hline \multirow[t]{8}{*}{ Phenolics } & Ascorbic acids & $\begin{array}{l}\text { Reduction in autoinducer- } 2 \text { activities, spore production, and enterotoxin production in } \\
\text { Clostridium perfringens }\end{array}$ & [87] \\
\hline & Baicalein, Hamamelitannin & $\begin{array}{l}\text { Inhibition of biofilm formation increased permeability of vancomycin and reduced } \\
\text { production of staphylococcal enterotoxin in } S \text {. aureus }\end{array}$ & {$[8 \underline{8}, 89]$} \\
\hline & Curcumin & Attenuation of virulence in $P$. aeruginosa & [90] \\
\hline & Ellagic acids & $\begin{array}{l}\text { Inhibit biofilm production in } E \text {. corrodens; reduction of AHLs production in } E \text {. } \\
\text { carotovora. }\end{array}$ & [91] \\
\hline & $\begin{array}{l}\text { Epigallocatechin gallate, } \\
\text { Catechin }\end{array}$ & $\begin{array}{l}\text { Interference with biofilm formation of } E \text {. coli and } P \text {. putida. Reduction in extracellu- } \\
\text { lar polymeric substance of Staphylococcus sp. }\end{array}$ & {$[6 \underline{5}, 92,93]$} \\
\hline & Ferulic acids & $\begin{array}{l}\text { Inhibition of biofilm in } P \text {. aeruginosa, interference to the motility of } P \text {. fluorescens } \\
\text { and } B \text {. cereus }\end{array}$ & {$[94,95]$} \\
\hline & Gallic acids & Inhibition of biofilm in $S$. mutans & [96] \\
\hline & Giganteone A & Reduction of QS-related activity in $E$. coli biosensors & [97] \\
\hline $\begin{array}{l}\text { Phytochemical } \\
\text { Group }\end{array}$ & QSIs (Phytochemicals) & QS Activity & References \\
\hline \multirow[t]{8}{*}{ Phenolics } & Gingerone & Reduction in swarming and biofilm-forming capacity in $P$. aeruginosa PAO1 & [98] \\
\hline & $\begin{array}{l}\text { Glycyrrhiza glabra flavo- } \\
\text { noids }\end{array}$ & $\begin{array}{l}\text { Interference of motility and reduction in biofilm formation in Acinetobacter bauman- } \\
\text { nii }\end{array}$ & [99] \\
\hline & Malabaricone C & Reduction in pyocyanin production and biofilm formation in $P$. aeruginosa & {$[100]$} \\
\hline & Rosamarinic acid & $\begin{array}{l}\text { Influence the protease and elastase production, biofilm formation, and virulence fac- } \\
\text { tors of } P \text {. aeruginosa }\end{array}$ & [1이 \\
\hline & Salicylic acids & $\begin{array}{l}\text { Reduction of AHL production, interference towards twitching and swimming motility } \\
\text { of } P \text {. aeruginosa }\end{array}$ & [1이 \\
\hline & $\begin{array}{l}\text { Tea polyphenols (Camellia } \\
\text { sinensis L.) }\end{array}$ & $\begin{array}{l}\text { Reduction of proteolytic activity, elastase, swarming motility, and biofilm formation } \\
\text { in P. aeruginosa }\end{array}$ & {$[\underline{103}]$} \\
\hline & Pyrizine-2-carboxylic acid & Inhibition of biofilm formation in multidrug-resistant $V$. cholerae & {$[104]$} \\
\hline & Proanthocyanidins & Reduction in production of QS-regulated virulence determinants in P. aeruginosa & {$[105]$} \\
\hline $\begin{array}{l}\text { Phytochemical } \\
\text { Group }\end{array}$ & QSIs (Phytochemicals) & QS Activity & References \\
\hline \multirow[t]{8}{*}{ Essential Oils } & $\begin{array}{l}\text { Cinnamon oil, Ferula oil, } \\
\text { Dorema oil }\end{array}$ & $\begin{array}{l}\text { Interference of QS related phenotypes; production of pyocyanin, alginate, and rham- } \\
\text { nolipid in } P \text {. aeruginosa }\end{array}$ & {$[106,107]$} \\
\hline & Cinnamon bark oil & $\begin{array}{l}\text { Modification of permeability of outer membrane and inhibition of bacterial QS- } \\
\text { activity in E. coli }\end{array}$ & {$[108]$} \\
\hline & Clove oil & $\begin{array}{l}\text { Reduction of violacein production in } C \text {. violaceum and interference of swarming } \\
\text { ability of } P \text {. aeruginosa }\end{array}$ & {$[109]$} \\
\hline & Coriander oil & $\begin{array}{l}\text { Inhibition of biofilm formation and lipid peroxidation in Campylobacter coli and } C \text {. } \\
\text { jejuni }\end{array}$ & [1110] \\
\hline & Linalool & Inhibition of biofilm formation and alteration of the adhesion of $A$. baumannii & [111] \\
\hline & Oregano oil & Inhibition of violacein production by $C$. violaceum & [112] \\
\hline & $\begin{array}{l}\text { Rose oil, Geranium oil, } \\
\text { lavender oil, Rosemary oil }\end{array}$ & Reduction in violacein pigmentation in $C$. violaceum and AHLs production in $E$. coli & {$[113]$} \\
\hline & Thyme oil & $\begin{array}{l}\text { Reduction of flagella gene expression in C. violaceum and interference of biofilm } \\
\text { formation in P. fluorescens KM121 }\end{array}$ & {$[114,115]$} \\
\hline $\begin{array}{l}\text { Phytochemical } \\
\text { Group }\end{array}$ & QSIs (Phytochemicals) & QS Activity & References \\
\hline \multirow[t]{4}{*}{ Isothiocyanates } & Allicin, Ajoene & Renders $P$. aeruginosa sensitive towards tobramycin; inhibition of biofilm & {$[116,117]$} \\
\hline & Allyl isothiocyanate & $\begin{array}{l}\text { Interference of adhesion and motility, inhibition of biofilm formation in } E \text {. coli, } S \text {. } \\
\text { aureus, L. monocytogenes, and P. aeruginosa }\end{array}$ & {$[7 \underline{1}, \underline{118-120]}$} \\
\hline & Iberin & $\begin{array}{l}\text { Interference of rhamnolipid production and gene expression of las } B \text { and } r h l A \text { in } P \text {. } \\
\text { aeruginosa }\end{array}$ & {$[1 \underline{121}, \underline{122}]$} \\
\hline & Sulforaphane, Erucin & $\begin{array}{l}\text { Antagonists of transcriptional activator of LasR and inhibition of biofilm formation in } \\
\text { P. aeruginosa }\end{array}$ & {$[\underline{123}]$} \\
\hline Stilbenoids & $\begin{array}{l}\text { Resveratrol, Piceatannol, } \\
\text { Oxyresveratrol }\end{array}$ & $\begin{array}{l}\text { Reduction of violacein in } C \text {. violaceum } \mathrm{CV} 026 \text {; Decreased in production of pyocya- } \\
\text { nin and swarming motility in } P \text {. aeruginosa PAO1 }\end{array}$ & {$[\underline{124}]$} \\
\hline
\end{tabular}




\section{Author Contributions}

The literature search, data extraction, and manuscript writing were performed by TW-S, LJW-F, LLN-S, and VL. At the same time, K-GC provided vital guidance, insight, and technical support to complete the project.

\section{Conflict of Interest}

The authors declared that research and writing were conducted in the absence of financial and non-financial interest. The funders do not participate or influence any of the experimental design, research, or writing work. This research was completed in the absence of any commercial or financial relationships construed as a potential conflict of interest.

\section{References}

1. Mukherjee S and Bassler BL. Bacterial quorum sensing in complex and dynamically changing environments. Nat Rev Microbiol, 2019; 17(6): 371-82.

2. Miller MB and Bassler BL. Quorum sensing in bacteria. Annu Rev Microbiol, 2001; 55(1): 165-199.

3. Tan W-S, Law JW-F, Letchumanan V, et al. Decoding the mystery of how bacteria "talk": Among Gram-negative microorganisms. Prog Microbes Mol Biol, 2019; 2(1): a0000038

4. Li Z and Nair SK. Quorum sensing: How bacteria can coordinate activity and synchronize their response to external signals? Protein Sci, 2012; 21(10): 1403-1417

5. Case RJ, Labbate M, and Kjelleberg S. AHL-driven quorum-sensing circuits: Their frequency and function among the Proteobacteria. ISME J, 2008; 2(4): 345-349.

6. Passos da Silva D, Schofield MC, Parsek MR, et al. An update on the sociomicrobiology of quorum sensing in gram-negative biofilm development. Pathogens 2017; 6(4): 51

7. Smith JL, Fratamico PM, and Gunther IV NW. Chapter 3: Shiga toxin-producing Escherichia coli, in Adv. Appl. Microbiol. 2014, Elsevier. p. 145-197.

8. Kher H-L, Krishnan T, Letchumanan V, et al. Characterization of quorum sensing genes and N-acyl homoserine lactones in Citrobacter amalonaticus strain YG6. Gene, 2019; 684: 58-69.

9. Decho AW, Norman RS, and Visscher PT. Quorum sensing in natural environments: Emerging views from microbial mats. Trends Microbiol, 2010; 18(2): 73-80.

10. Galloway WR, Hodgkinson JT, Bowden SD, et al. Quorum sensing in Gram-negative bacteria: Small-molecule modulation of AHL and AI-2 quorum sensing pathways. Chem Rev, 2011; 111(1): 28-67.

11. Nadell CD, Xavier JB, Levin SA, et al. The evolution of quorum sensing in bacterial biofilms. PLoS Biol, 2008; 6(1): e14.

12. Parsek MR and Greenberg EP. Acyl-homoserine lactone quorum sensing in gram-negative bacteria: A signaling mechanism involved in associations with higher organisms. Proc Natl Acad Sci USA, 2000; 97(16): 8789-8793

13. Geske GD, Wezeman RJ, Siegel AP, et al. Small molecule inhibitors of bacterial quorum sensing and biofilm formation. J Am Chem Soc, 2005; 127(37): 12762-12763.

14. Annous BA, Fratamico PM, and Smith JL. Scientific status summary: Quorum sensing in biofilms: Why bacteria behave the way they do. J Food Sci, 2009; 74(1): R24-R37.

15. Parsek MR and Greenberg E. Sociomicrobiology: The connections between quorum sensing and biofilms. Trends Microbiol, 2005; 13(1): 27-33.

16. Labbate M, Queck SY, Koh KS, et al. Quorum sensing-controlled biofilm development in Serratia liquefaciens MG1. J Bacteriol, 2004; 186(3): 692-698

17. Huber B, Riedel K, Hentzer M, et al. The cep quorum-sensing system of Burkholderia cepacia H111 controls biofilm formation and swarming motility. Microbiology, 2001; 147(9): 2517-2528.

18. Merritt J, Qi F, Goodman SD, et al. Mutation of luxS affects biofilm formation in Streptococcus mutans. Infect Immun, 2003; 71(4): 1972-1979.

19. Yoshida A, Ansai T, Takehara T, et al. LuxS-based signaling affects Streptococcus mutans biofilm formation. Appl Environ Microbiol, 2005; 71(5): 2372-2380.

20. Puskas A, Greenberg Eá, Kaplan S, et al. A quorum-sensing system in the free-living photosynthetic bacterium Rhodobacter sphaeroides. J Bacteriol, 1997; 179(23): 7530-7537.

21. Joint I, Allan Downie J, and Williams P. Bacterial conversations: Talking, listening and eavesdropping. An introduction. Philos Trans R Soc Lond, Ser B: Biol Sci, 2007; 362(1483): 1115-1117.

22. Kalia VC, Quorum sensing inhibitors: An overview. Biotechnol
Adv, 2013; 31(2): 224-245.

23. Ivanova K, Fernandes M, and Tzanov T. Current advances on bacterial pathogenesis inhibition and treatment strategies, in Microbial pathogens and strategies for combating them: Science, technology and education, A. Méndez-Vilas, Editor. 2013, Formatex Research Center. p. 322-336.

24. Kemung HM, Tan LT-H, Chan K-G, et al. Streptomyces sp. strain MUSC 125 from mangrove soil in Malaysia with anti-MRSA, anti-biofilm and antioxidant activities. Molecules, 2020; 25(15): 3545.

25. Teerawattanapong N, Panich P, Kulpokin D, et al. A systematic review of the burden of multidrug-resistant healthcare-associated infections among intensive care unit patients in Southeast Asia: The rise of multidrugresistant Acinetobacter baumannii. Infect Control Hosp Epidemiol, 2018; 39(5): 525-533.

26. DeLeo FR and Chambers HF. Reemergence of antibiotic-resistant Staphylococcus aureus in the genomics era. J Clin Invest, 2009; 119(9): 2464-2474.

27. Kemung HM, Tan LT-H, Khan TM, et al. Streptomyces as a prominent resource of future anti-MRSA drugs. Front Microbiol, 2018; 9: 2221

28. Monroe S and Polk R, Antimicrobial use and bacterial resistance. Curr Opin Microbiol, 2000; 3(5): 496-501.

29. Yoke-Kqueen C, Learn-Han L, Noorzaleha A, et al. Characterization of multiple-antimicrobial-resistant Salmonella enterica Subsp. enterica isolated from indigenous vegetables and poultry in Malaysia. Lett Appl Microbiol, 2008; 46(3): 318-324.

30. Learn-Han L, Yoke-Kqueen C, Shiran M, et al. Molecular characterization and antimicrobial resistance profiling of Salmonella enterica subsp. enterica isolated from 'Selom'(Oenanthe stolonifera). Int Food Res J, 2009; 16(1): 191-202

31. Eng S-K, Pusparajah P, Ab Mutalib N-S, et al. Salmonella: A review on pathogenesis, epidemiology and antibiotic resistance. Front Life Sci, 2015; 8(3): 284-293.

32. Komolafe O. Antibiotic resistance in bacteria-an emerging public health problem. Malawi Med J, 2003; 15(2): 63-67.

33. Letchumanan V, Ab Mutalib N-S, Wong SH, et al. Determination of antibiotic resistance patterns of Vibrio parahaemolyticus from shrimp and shellfish in Selangor, Malaysia. Prog Microbes Mol Biol, 2019; 2(1): a0000019.

34. Lee L-H, Ab Mutalib N-S, Law JW-F, et al. Discovery on antibiotic resistance patterns of Vibrio parahaemolyticus in Selangor reveals carbapenemase producing Vibrio parahaemolyticus in marine and freshwater fish. Front Microbiol, 2018; 9: 2513.

35. Loo KY, Letchumanan V, Law JWF, et al. Incidence of antibiotic resistance in Vibrio spp. Rev Aqua, 2020: 1-19.

36. Lee L-H and Raghunath P. Vibrionaceae diversity, multidrug resistance and management. Front Microbiol, 2018; 9: 563.

37. Letchumanan V, Chan K-G, and Lee L-H. Vibrio parahaemolyticus: A review on the pathogenesis, prevalence, and advance molecular identification techniques. Front Microbiol, 2014; 5: 705.

38. Letchumanan V, Pusparajah P, Tan LT-H, et al. Occurrence and antibiotic resistance of Vibrio parahaemolyticus from shellfish in Selangor, Malaysia. Front Microbiol, 2015; 6: 1417.

39. Letchumanan V, Yin W-F, Lee L-H, et al. Prevalence and antimicrobial susceptibility of Vibrio parahaemolyticus isolated from retail shrimps in Malaysia. Front Microbiol, 2015; 6: 33.

40. Letchumanan V, Chan K-G, Pusparajah P, et al. Insights into bacteriophage application in controlling Vibrio species. Front Microbiol, 2016; 7: 1114 .

41. Letchumanan V, Chan K-G, Khan TM, et al. Bile sensing: the activation of Vibrio parahaemolyticus virulence. Front Microbiol, 2017; 8: 728

42. Letchumanan V, Loo K-Y, Law JW-F, et al. Vibrio parahaemolyticus: The protagonist of foodborne diseases. Prog Microbes Mol Biol, 2019; The prota.
2(1).

43. Lee L-H, Goh B-H, and Chan K-G. Actinobacteria: Prolific producers of bioactive metabolites. Front Microbiol, 2020; 11: 1612.

44. Law JW-F, Letchumanan V, Tan LT-H, et al. The rising of "modern Actinobacteria" era. Prog Microbes Mol Biol, 2020; 3(1): a0000064.

45. Law JW-F, Pusparajah P, Ab Mutalib N-S, et al. A review on mangrove actinobacterial diversity: The roles of Streptomyces and novel species discovery. Prog Microbes Mol Biol, 2019; 1(1): a0000024.

46. Aw Y-K, Ong K-S, Lee L-H, et al. Newly isolated Paenibacillus tyrfis sp. nov., from Malaysian tropical peat swamp soil with broad spectrum antimicrobial activity. Front Microbiol, 2016; 7: 219.

47. Lee L-H, Chan K-G, Stach J, et al. The search for biological active agent (s) from actinobacteria. Front Microbiol, 2018; 9: 824

48. Azman A-S, Othman I, Fang C-M, et al. Antibacterial, anticancer and neuroprotective activities of rare Actinobacteria from mangrove forest soils. Indian J Microbiol, 2017; 57(2): 177-187.

49. Taylor PW, Alternative natural sources for a new generation of antibacterial agents. Int. J. Antimicrob. Agents, 2013; 42(3): 195-201.

50. Winzer K, Hardie KR, and Williams P. Bacterial cell-to-cell communication: Sorry, can't talk now-gone to lunch! Curr Opin Microbiol, 2002; 5(2): 216-222.

51. Kim SY, Lee SE, Kim YR, et al. Regulation of Vibrio vulnificus virulence by the LuxS quorum-sensing system. Mol Microbiol, 2003; 48(6): $1647-1664$.

52. Turan NB and Engin GÖ. Chapter 4: Quorum quenching, in Comprehensive Analytical Chemistry. 2018, Elsevier. p. 117-149.

53. Basavaraju M, Sisnity VS, Palaparthy R, et al. Quorum quenching: signal jamming in dental plaque biofilms. J Dent Sci, 2016; 11(4): 349-352.

54. Rehman ZU and Leiknes T. Quorum-quenching bacteria isolated from Red Sea sediments reduce biofilm formation by Pseudomonas aeruginosa. Front Microbiol, 2018; 9: 1354.

55. Janssens JC, Steenackers H, Robijns S, et al. Brominated furanones inhibit biofilm formation by Salmonella enterica serovar Typhimurium. 
Appl Environ Microbiol, 2008; 74(21): 6639-6648

56. Givskov M, de Nys R, Manefield M, et al. Eukaryotic interference with homoserine lactone-mediated prokaryotic signalling. J Bacteriol, 1996; 178(22): 6618-6622.

57. Defoirdt T, Crab R, Wood TK, et al. Quorum sensing-disrupting brominated furanones protect the gnotobiotic brine shrimp Artemia franciscana from pathogenic Vibrio harveyi, Vibrio campbellii, and Vibrio parahaemolyticus isolates. Appl Environ Microbiol, 2006; 72(9): 6419-6423.

58. Park S-Y, Kang H-O, Jang H-S, et al. Identification of extracellular $\mathrm{N}$-acylhomoserine lactone acylase from a Streptomyces sp. and its application to quorum quenching. Appl Environ Microbiol, 2005, 71(5): 2632-2641

59. Xu F, Byun T, Dussen H-J, et al. Degradation of N-acylhomoserine lactones, the bacterial quorum-sensing molecules, by acylase. J Biotechnol, 2003; 101(1): 89-96.

60. Thomas PW, Stone EM, Costello AL, et al. The quorum-quenching lactonase from Bacillus thuringiensis is a metalloprotein. Biochemistry, 2005; 44(20): 7559-7569.

61. Romero M, Acuña L, and Otero A. Patents on quorum quenching: interfering with bacterial communication as a strategy to fight infections. Recent Pat Biotectnol, 2012; 6(1): 2-12.

62. Koh C-L, Sam C-K, Yin W-F, et al. Plant-derived natural products as sources of anti-quorum sensing compounds. Sens, 2013; 13(5): 62176228.

63. Nazzaro F, Fratianni F, and Coppola R. Quorum sensing and phytochemicals. Int J Mol Sci, 2013; 14(6): 12607-12619.

64. Jagani S, Chelikani R, and Kim D-S. Effects of phenol and natural phenolic compounds on biofilm formation by Pseudomonas aeruginosa. Biofouling, 2009; 25(4): 321-324.

65. Vandeputte OM, Kiendrebeogo M, Rajaonson S, et al. Identification of catechin as one of the flavonoids from Combretum albiflorum bark extract that reduces the production of quorum-sensing-controlled virulence factors in Pseudomonas aeruginosa PAO1. Appl Environ Microbiol, 2010; 76(1): 243-253.

66. Vikram A, Jayaprakasha GK, Jesudhasan P, et al. Suppression of bacterial cell-cell signalling, biofilm formation and type III secretion system by citrus flavonoids. J Appl Microbiol, 2010; 109(2): 515-527.

67. Lee J-H, Regmi SC, Kim J-A, et al. Apple flavonoid phloretin inhibits Escherichia coli O157: H7 biofilm formation and ameliorates colon inflammation in rats. Infect. Immun, 2011; 79(12): 4819-4827.

68. Rasamiravaka T, Labtani Q, Duez $\mathrm{P}$ et al. The formation of biofilms by Pseudomonas aeruginosa: A review of the natural and synthetic compounds interfering with control mechanisms. BioMed Res Int, 2015; 2015: 759348 .

69. Girennavar B, Cepeda ML, Soni KA, et al. Grapefruit juice and its furocoumarins inhibits autoinducer signaling and biofilm formation in bacteria. Int J Food Microbiol, 2008; 125(2): 204-208.

70. Wojdyło A, Oszmiański J, and Czemerys R. Antioxidant activity and phenolic compounds in 32 selected herbs. Food Chem, 2007; 105(3): 940-949.

71. Plyuta V, Zaitseva J, Lobakova E, et al. Effect of plant phenolic compounds on biofilm formation by Pseudomonas aeruginosa. APMIS, 2013; 121(11): 1073-1081.

72. Matsunaga T, Nakahara A, Minnatul KM, et al. The inhibitory effects of catechins on biofilm formation by the periodontopathogenic bacterium, Eikenella corrodens. Biosci, Biotechnol, Biochem, 2010; 74(2): 2445-2450.

73. Borges A, Saavedra MJ, and Simões M. The activity of ferulic and gallic acids in biofilm prevention and control of pathogenic bacteria. Biofouling, 2012; 28(7): 755-767.

74. Fenwick GR, Heaney RK, Mullin WJ, et al. Glucosinolates and their breakdown products in food and food plants. Crit Rev Food Sci Nutr, 1983; 18(2): 123-201.

75. Lee H-Y, Zou Y, and Ahn J. Physiochemical and molecular properties of antimicrobial-exposed Staphylococcus aureus during the planktonicto-biofilm transition. Ann Microbiol, 2013; 63(3): 1213-1217.

76. Sadekuzzaman M, Yang S, Mizan M, et al. Current and recent advanced strategies for combating biofilms. Compr Rev Food Sci Food Saf, 2015; 14(4): 491-509.

77. Packiavathy IASV, Agilandeswari P, Musthafa KS, et al. Antibiofilm and quorum sensing inhibitory potential of Cuminum cyminum and its secondary metabolite methyl eugenol against Gram negative bacterial pathogens. Food Res Int 2012; 45(1): 85-92.

78. De Kievit TR and Iglewski BH. Bacterial quorum sensing in pathogenic relationships. Infect Immun, 2000; 68(9): 4839-4849.

79. Di Cagno R, De Angelis M, Calasso M, et al. Proteomics of the bacterial cross-talk by quorum sensing. J Proteomics, 2011; 74(1): $19-34$.

80. Goldenfeld N and Woese C. Biology's next revolution. Nature, 2007; 445(7126): 369-369.

81. Hartmann A and Schikora A. Quorum sensing of bacteria and transkingdom interactions of $\mathrm{N}$-acyl homoserine lactones with eukaryotes. J Chem Ecol, 2012; 38(6): 704-713.

82. Ali B, Sabri A, Ljung K, et al. Auxin production by plant associated bacteria: Impact on endogenous IAA content and growth of Triticum aestivum L. Lett Appl Microbiol, 2009; 48(5): 542-547.

83. Tu C, Zheng $\mathrm{C}$, and Chen $\mathrm{H}$. Effect of applying chemical fertilizers on forms of lead and cadmium in red soil. Chemosphere, 2000; 41(1-2): 133-138.

84. Von Rad U, Klein I, Dobrev PI, et al. Response of Arabidopsis thaliana to N-hexanoyl-DL-homoserine-lactone, a bacterial quorum sensing molecule produced in the rhizosphere. Planta, 2008; 229(1): 73-85.

85. Götz C, Fekete A, Gebefuegi I, et al. Uptake, degradation and chiral discrimination of $\mathrm{N}$-acyl-D/L-homoserine lactones by barley (Hordeum vulgare) and yam bean (Pachyrhizus erosus) plants. Anal Bioanal Chem, 2007; 389(5): 1447-1457.

86. Daniels R, De Vos DE, Desair J, et al. The cin quorum sensing locus of Rhizobium etli CNPAF512 affects growth and symbiotic nitrogen fixation. J Biol Chem, 2002; 277(1): 462-468.

87. Baird-Parker A and Freame B. Combined effect of water activity, $\mathrm{pH}$ and temperature on the growth of Clostridium botulinum from spore and vegetative cell inocula. J Appl Bacteriol, 1967; 30(3): 420-429.

88. Brackman G, Breyne K, De Rycke R, et al. The quorum sensing inhibitor hamamelitannin increases antibiotic susceptibility of Staphylococcus aureus biofilms by affecting peptidoglycan biosynthesis and eDNA release. Sci Rep, 2016; 6: 20321.

89. Chen Y, Liu T, Wang K, et al. Baicalein inhibits Staphylococcus aureus biofilm formation and the quorum sensing system in vitro. PLoS One, 2016; 11(4): e0153468.

90. Rudrappa T and Bais HP. Curcumin, a known phenolic from Curcuma longa, attenuates the virulence of Pseudomonas aeruginosa PAO1 in whole plant and animal pathogenicity models. J Agric Food Chem, 2008; 56(6): 1955-1962.

91. Truchado P, Larrosa M, Castro-Ibáñez I, et al. Plant food extracts and phytochemicals: Their role as quorum sensing inhibitors. Trends Food Sci Technol, 2015; 43(2): 189-204.

92. Lee K-M, Kim W-S, Lim J, et al. Antipathogenic properties of green tea polyphenol epigallocatechin gallate at concentrations below the MIC against enterohemorrhagic Escherichia coli O157: H7. J Food Prot, 2009; 72(2): 325-331.

93. $\mathrm{Xu}$ X, Zhou XD, and $\mathrm{Wu} \mathrm{CD}$. Tea catechin epigallocatechin gallate inhibits Streptococcus mutans biofilm formation by suppressing $g t$ genes. Arch Oral Biol, 2012; 57(6): 678-683.

94. Lemos M, Borges A, Teodósio J, et al. The effects of ferulic and salicylic acids on Bacillus cereus and Pseudomonas fluorescens single-and dualspecies biofilms. Int Biodeterior Biodegrad, 2014; 86: 42-51.

95. Zeng Z, Qian L, Cao L, et al. Virtual screening for novel quorum sensing inhibitors to eradicate biofilm formation of Pseudomonas aeruginosa. Appl Microbiol Biotechnol, 2008; 79(1): 119.

96. Kang M-S, Oh J-S, Kang I-C, et al. Inhibitory effect of methyl gallate and gallic acid on oral bacteria. J Microbiol, 2008; 46(6): 744-750.

97. Sivasothy Y, Krishnan T, Chan K-G, et al. Quorum sensing inhibitory activity of giganteone a from Myristica cinnamomea king against Escherichia coli biosensors. Molecules, 2016; 21(3): 391.

98. Kumar L, Chhibber S, Kumar R, et al. Zingerone silences quorum sensing and attenuates virulence of Pseudomonas aeruginosa. Fitoterapia, 2015; 102: 84-95.

99. Bhargava N, Singh SP, Sharma A, et al. Attenuation of quorum sensingmediated virulence of Acinetobacter baumannii by Glycyrrhiza glabra flavonoids. Future Microbiol, 2015; 10(12): 1953-1968.

100. Chong YM, Yin WF, Ho CY, et al. Malabaricone C from Myristica cinnamomea exhibits anti-quorum sensing activity. J Nat Prod, 2011; 74(10): 2261-2264.

101. Marwat SK, Khan MS, Ghulam S, et al. Phytochemical constituents and pharmacological activities of sweet Basil-Ocimum basilicum L.(Lamiaceae). Asian J Chem, 2011; 23(9): 3773.

102. Bandara MB, Zhu H, Sankaridurg PR, et al. Salicylic acid reduces the production of several potential virulence factors of Pseudomonas aeruginosa associated with microbial keratitis. Invest Ophthalmol Vis Sci, 2006; 47(10): 4453-4460.

103. Yin H, Deng Y, Wang H, et al. Tea polyphenols as an antivirulence compound disrupt quorum-sensing regulated pathogenicity of Pseudomonas aeruginosa. Sci Rep 2015; 5: 16158

104. Hema M, Princy SA, Sridharan V, et al. Synergistic activity of quorum sensing inhibitor, pyrizine-2-carboxylic acid and antibiotics against multi-drug resistant $V$. cholerae. RSC Adv, 2016; 6(51): 45938-45946.

105. Maisuria VB, Lopez-de Los Santos Y, Tufenkji N, et al. Cranberryderived proanthocyanidins impair virulence and inhibit quorum sensing of Pseudomonas aeruginosa. Sci Rep, 2016; 6: 30169.

106. Kalia M, Yadav VK, Singh PK, et al. Effect of cinnamon oil on quorum sensing-controlled virulence factors and biofilm formation in Pseudomonas aeruginosa. PLoS One, 2015; 10(8): e0135495.

107. Sepahi E, Tarighi S, Ahmadi FS, et al. Inhibition of quorum sensing in Pseudomonas aeruginosa by two herbal essential oils from Apiaceae family. J Microbiol, 2015; 53(2): 176-180.

108. Yap P, Krishnan T, Chan K-G, et al. Antibacterial mode of action of Cinnamomum verum bark essential oil, alone and in combination with piperacillin, against a multi-drug-resistant Escherichia coli strain. J Microbiol Biotechnol, 2015; 25(8): 1299-1306.

109. Khan MSA, Zahin M, Hasan S, et al. Inhibition of quorum sensing regulated bacterial functions by plant essential oils with special reference to clove oil. Lett Appl Microbiol, 2009; 49(3): 354-360.

110. Duarte A, Luís Â, Oleastro M, et al. Antioxidant properties of coriander essential oil and linalool and their potential to control Campylobacter spp. Food Control, 2016; 61: 115-122.

111. Alves S, Duarte A, Sousa S, et al. Study of the major essential oil compounds of Coriandrum sativum against Acinetobacter baumanni and the effect of linalool on adhesion, biofilms and quorum sensing. Biofouling, 2016; 32(2): 155-165.

112. Rodriguez-Garcia I, Cruz-Valenzuela MR, Silva-Espinoza BA, et al. Oregano (Lippia graveolens) essential oil added within pectin edible coatings prevents fungal decay and increases the antioxidant capacity of treated tomatoes. J Sci Food Agric, 2016; 96(11): 3772-3778. 
113. Szabó MÁ, Varga GZ, Hohmann J, et al. Inhibition of quorumsensing signals by essential oils. Phytother Res, 2010; 24(5): 782 786.

114. Myszka K, Schmidt MT, Majcher M, et al. Inhibition of quorum sensing-related biofilm of Pseudomonas fluorescens KM121 by Thymus vulgare essential oil and its major bioactive compounds. Int Biodeterior Biodegrad, 2016; 114: 252-259.

115. Vattem DA, Mihalik K, Crixell SH, et al. Dietary phytochemicals as quorum sensing inhibitors. Fitoterapia, 2007; 78(4): 302-310.

116. Bjarnsholt T, Jensen PØ, Rasmussen TB, et al. Garlic blocks quorum sensing and promotes rapid clearing of pulmonary Pseudomonas aeruginosa infections. Microbiol, 2005; 151(12): 3873-3880.

117. Jakobsen TH, van Gennip M, Phipps RK, et al. Ajoene, a sulfurrich molecule from garlic, inhibits genes controlled by quorum sensing Antimicrob Agents Chemother, 2012; 56(5): 2314-2325.

118. Borges A, Simões LC, Saavedra MJ, et al. The action of selected isothiocyanates on bacterial biofilm prevention and control. Int Biodeterior Biodegrad, 2014; 86: 25-33.
119. de Saravia SGG and Gaylarde CC. The antimicrobial activity of an aqueous extract of Brassica negra. Int Biodeterior Biodegrad, 1998; 41(2): 145-148.

120. Guiamet $P$ and Gómez de Saravia S. Laboratory studies of biocorrosion control using traditional and environmentally friendly biocides: An overview. Lat Am Appl Res, 2005; 35(4): 295-300.

121. Galloway WR, Hodgkinson JT, Bowden S, et al. Applications of small molecule activators and inhibitors of quorum sensing in Gram-negative bacteria. Trends Microbiol, 2012; 20(9): 449-458.

122. Jakobsen TH, Bjarnsholt T, Jensen PØ, et al. Targeting quorum sensing in Pseudomonas aeruginosa biofilms: Current and emerging inhibitors. Future Microbiol, 2013; 8(7): 901-921.

123. Ganin H, Rayo J, Amara N, et al. Sulforaphane and erucin, natural isothiocyanates from broccoli, inhibit bacterial quorum sensing. Med Chem Commun, 2013; 4(1): 175-179.

124. Sheng J-Y, Chen T-T, Tan X-J, et al. The quorum-sensing inhibiting effects of stilbenoids and their potential structure-activity relationship. Bioorg Med Chem Lett, 2015; 25(22): 5217-5220. 